\title{
A OCUPAÇÃO DA ZONA RURAL COM FINS URBANOS, O ORDENAMENTO TERRITORIAL PELO MUNICÍPIO E A CIDADE SUSTENTÁVEL
}

\author{
Patricia Cavalcanti Albuquerque ${ }^{1}$ \\ Marcos Prado de Albuquerque
}

\section{RESUMO:}

O presente trabalho, através do método de pesquisa bibliográfico, busca tecer reflexões sobre a ocupação da zona rural com fins urbanos e o ordenamento territorial pelo município a partir das funções socioambientais da propriedade e da cidade, e do direito à cidade sustentável, conforme diretrizes do Estatuto da Cidade. A Constituição Federal atribui ao Município o dever de promover o adequado ordenamento territorial e a execução da política urbana, devendo realizar o planejamento do seu território como um todo através do Plano Diretor, incluindo as atividades desenvolvidas na zona rural, visando implementar o direito à cidade sustentável.

Palavras-chave: Direito Urbanístico; Cidade sustentável; Função socioambiental da propriedade; Política urbana; Plano Diretor

\section{THE OCCUPATION OF THE RURAL AREA WITH URBAN PURPOSES, THE TERRITORIAL ORDINATION BY THE MUNICIPALITY AND THE SUSTAINABLE CITY}

\begin{abstract}
:
The present work, through the method of bibliographical research, seeks to reflect on the occupation of rural area for urban purposes and the territorial planning by the municipality based on social and environmental functions of property and city, and the right to sustainable city, according to guidelines of the Statute of the City. Federal Constitution assigns to the Municipality the duty to promote proper territorial planning and urban policy implementation, and to carry out the planning of its territory as a whole through Master Plan, including activities developed in rural area, aiming to implement the right to the city Sustainable.
\end{abstract}

Keywords: Urban Law; Sustainable city; Socio-environmental function of property; Urban policy; Master plan

\section{Introdução}

Os dados dos Censos Demográficos brasileiros produzidos a partir da segunda metade do século XX mostram grande incremento da população urbana, com um decréscimo

\footnotetext{
${ }^{1}$ Possui graduação em Direito pela Universidade Federal de Mato Grosso (2002). Mestrado em andamento em DIREITO AGROAMBIENTAL. Universidade Federal de Mato Grosso, UFMT.

${ }_{2}^{2}$ Possui graduação em Ciências Jurídicas e Sociais pela Universidade Federal do Rio de Janeiro (1979), Mestrado em Direito pela Pontifícia Universidade Católica do Rio de Janeiro (1982) e Doutorado em Direito pela Universidade de São Paulo (1991).
} 
significativo da população rural (NAKANO, 2004), sendo que hoje, no Brasil, a maior parte da população vive em zona urbana.

A diminuição do volume da população rural, paralelamente ao incremento da população urbana, indica a tendência de aumento da urbanização no Brasil que, a partir de 1950, deixa de ser um país de características rurais para caminhar no sentido de um país mais urbanizado.

Com a modernização das atividades agrícolas, houve o desenvolvimento de ocupação com fins urbanos na zona rural, ocorrendo uma crescente conversão de terras rurais em urbanas, mediante uma lógica que não promove a inclusão social e a sustentabilidade do ambiente (SANTORO, 2004).

Num contexto de cidade sustentável que surge a partir da Lei Federal n. ${ }^{\circ}$ 10.257, de 10 de julho de 2001, autodenominada Estatuto das Cidades, a adequada organização do solo, tanto na zona urbana como na zona rural, é de suma importância, visando coibir ilegalidades e evitar a degradação do meio ambiente natural e urbano.

Conforme Daniella Maria dos Santos Dias (2012, p. 56),

as cidades se expandem, reproduzindo a acumulação capitalista no espaço, construindo-o e transformando-o. A expansão da cidade - que avança para as áreas rurais, alterando-as ou mesmo destruindo-as - é acompanhada de uma degradação da qualidade de vida e da própria realidade urbanística.

Nesse panorama, necessária a análise da ocupação com finalidade urbana na área rural dos municípios, sobre a qual deve haver a atuação do Poder Público municipal visando ao atendimento das funções sociais da propriedade e da cidade, bem como garantir o direito à cidade sustentável para as presentes e futuras gerações, diante dos ditames constitucionais.

Para o desenvolvimento do trabalho, optou-se por abordar, utilizando o método de pesquisa bibliográfica, em um primeiro momento, os diferentes significados para o rural e o urbano e sobre a necessidade do adequado ordenamento territorial e desenvolvimento do município. A intenção é analisar a qualificação urbana e rural, a ocupação da zona rural com fins urbanos, a integração entre a área urbana e a rural e o devido ordenamento do território como um todo para possibilitar o desenvolvimento sustentável no município.

Logo após, passa-se a analisar as funções socioambientais da propriedade e da cidade em relação às ocupações em áreas rurais com fins urbanos, nos termos do que dispõe a Constituição Federal e a legislação infraconstitucional vigente, que impõe o dever de a propriedade privada obedecer à função socioambiental, sendo que, em relação à propriedade 
rural, é necessário ainda o cumprimento a determinações econômicas (aproveitamento racional e adequado); ambientais (utilização adequada dos recursos naturais disponíveis e preservação do meio ambiente); e sociais (observância das disposições que regulam as relações de trabalho e exploração que favoreça o bem-estar dos proprietários e dos trabalhadores).

Em um terceiro momento, analisa-se as competências e atribuições dos entes públicos em relação ao ordenamento territorial e desenvolvimento do município, abrangendo a zona rural e a zona urbana, com o propósito de esclarecer sobre o importante papel e diretrizes a serem desempenhadas pela União, pelos Estados e pelo Município.

Por fim, serão verificadas, ainda, as possibilidades jurídicas de aplicação do Estatuto da Cidade e do Plano Diretor sobre a zona rural em termos de organização territorial, buscando-se examinar a hipótese da incidência do plano diretor e do Estatuto da Cidade sobre todo o território de um determinado município.

\section{O Rural e o urbano, o ordenamento territorial e o desenvolvimento sustentável dos municípios}

Há diferentes concepções e definições acerca do território urbano e rural, sendo importante sua devida compreensão para que se possa definir tributações e competências dos entes federativos (Município, Estado e União), bem como para fins de organização políticoadministrativa e territorial do município e para estabelecer a política tributária aplicável sobre a propriedade urbana e rural.

Assim, no nosso ordenamento, os qualificativos urbano e rural ora são identificados pela destinação dada ao solo, ora pela localização do imóvel, sendo que cada um dos critérios tem sua utilidade jurídica.

A noção de área urbana e de área rural pode variar significativamente conforme o critério adotado ou conforme o fim que se pretende atingir. Cada critério de classificação possui seus limites, sendo pertinente a determinadas hipóteses jurídicas enquanto em outras não pode ser aplicada.

A definição de imóvel rural conferida pelo Direito Agrário não é a mesma do Direito Civil. Pela ótica agrarista, a destinação que se dá ao imóvel ou à atividade nele exercida configura o principal elemento caracterizador do imóvel rural, e não sua localização, a qual pode ser urbana, inclusive. 
A Lei n. ${ }^{\circ}$ 4.504, de 30 de novembro de 1964 (Estatuto da Terra), define, em seu art. $4^{\circ}$, inciso I, o imóvel rural baseado na sua destinação, como sendo "o prédio rústico, de área contínua qualquer que seja a sua localização que se destina à exploração extrativa agrícola, pecuária ou agro-industrial, quer através de planos públicos de valorização, quer através de iniciativa privada."

Também a Lei $\mathrm{n}^{\circ} 8.629$, de 25 de fevereiro de 1993, que regulamentou dispositivos da Constituição Federal de 1988, repisa o conceito da destinação ou utilização, dizendo que: "Art. $4^{\circ}$ Para os efeitos desta lei, conceituam-se: I - Imóvel Rural - o prédio rústico de área contínua, qualquer que seja a sua localização, que se destine ou possa se destinar à exploração pecuária, extrativa vegetal, florestal ou agroindustrial".

Já o Código Tributário Nacional (Lei n. ${ }^{0} 5.172$, de 25 de outubro de 1966), para efeitos tributários, adota o critério da situação ou localização do imóvel, reputando como urbano o imóvel localizado em zona urbana e rural o que estiver fora desta zona (artigos 29 e $32)$.

Assim, não se confunde solo urbano e solo rural com zona urbana e zona rural, sendo que os dois primeiros referem-se à destinação de uso dada ao solo (ao imóvel), enquanto os dois últimos dizem respeito à localização do imóvel, independentemente da finalidade com que é utilizado.

Segundo o artigo 32, parágrafo primeiro, do Código Tributário Nacional, entende-se como zona urbana a definida em lei municipal, observado o requisito mínimo da existência de melhoramentos indicados em pelo menos 2 (dois) dos incisos seguintes, construídos ou mantidos pelo Poder Público:

I - meio-fio ou calçamento, com canalização de águas pluviais;

II - abastecimento de água;

III - sistema de esgotos sanitários;

$I V$ - rede de iluminação pública, com ou sem posteamento para distribuição domiciliar;

$V$ - escola primária ou posto de saúde a uma distância máxima de 3 (três) quilômetros do imóvel considerado.

$\$ 2 .{ }^{\circ}$ A lei municipal pode considerar urbanas as áreas urbanizáveis, ou de expansão urbana, constantes de loteamentos aprovados pelos órgãos competentes, destinados à habitação, à indústria ou ao comércio, mesmo que localizados fora das zonas definidas nos termos do parágrafo anterior.

Lei municipal também pode declarar áreas municipais como zonas de expansão urbana e zonas de urbanização específica, destinadas à habitação, à indústria ou ao comércio, mesmo que fora dos critérios definidos no $\$ 1^{\circ}$ do artigo 32 do Código Tributário Nacional, 
sendo a zona de expansão urbana a área reservada para o crescimento das cidades e vilas, adjacente a zona urbana, enquanto que a zona de urbanização específica está relacionada à possibilidade de serem exercidas atividades tipicamente urbanas em determinado terreno da cidade, separado, não contíguo às demais zonas urbanas do Município.

Assim, a destinação efetiva e predominante dos imóveis para certas atividades em um dado local tem poder decisivo na definição da natureza desses imóveis como urbanos ou rurais, ao lado do critério localização.

Essa orientação restou defendida em julgado da relatoria da Ministra Eliana Calmon, o qual estabeleceu que "O critério para a aferição da natureza do imóvel, para sua classificação, se urbano ou rural, para fins de desapropriação, leva em consideração não apenas sua localização geográfica, mas também a destinação do bem. Precedentes do STJ" (REsp 1170055/TO, Segunda Turma, DJ de 24/6/2010).

Portanto, hoje resta consolidada a orientação acerca de que o critério da destinação econômica é fundamental para definir a natureza do imóvel, independentemente de sua localização em zona urbana ou rural, seja para fins de desapropriação e pagamento da indenização em metro quadrado ou hectare, seja para fins tributários de incidência de IPTU ou ITR.

O INCRA, para fim de cadastro de imóvel rural e expedição do Certificado de cadastro de imóvel rural - CCIR, adotou o critério da destinação, retirando qualquer dúvida quanto à efetiva ou potencial exploração, bastando que o imóvel tenha características próprias de rural, para que assim seja considerado, independente de estar ou não sendo explorado.

Sobre essa duplicidade de qualificação do solo, uma para fins urbanísticos e outra para fins tributários, que resulta em obstáculos para o planejamento territorial ser efetuado de forma adequada, José Afonso da Silva (SILVA, 2008) afirma que:

O correto seria que a qualificação tributária fosse uma decorrência da
qualificação urbanística da propriedade imobiliária, que, por seu lado,
deveria defluir da qualificação urbanística do solo, a fim de que
harmonizassem os interesses tributários com os urbanísticos, de tal sorte
que o tributo urbano ou de efeito urbano constituísse instrumento auxiliar
da atividade urbanística porque o solo respectivo assim se qualifica. Por
isso não podemos apegar-nos à qualificação tributária do imóvel urbano
para chegarmos à qualificação urbanística do solo.

Para Sparovek (2004, p. 16), é preciso dispor de alguma classificação funcional para demarcar o que é urbano e o que é rural, sendo que, no urbano, os serviços e equipamentos 
urbanos (redes de infra-estrutura, serviços, atividades comerciais e industriais) estão consolidados e são contínuos; com alta densidade populacional e propriedades imobiliárias fragmentadas, podendo o urbano ser reconhecido pela extensão e oferta dos serviços públicos e pela densidade populacional e viária, podendo ou não existir produção agrícola. Já no rural, a extensão dos serviços e equipamentos públicos é restrita ou parcial, a dimensão das propriedades é muito maior e predominam as atividades agrícolas e áreas de preservação, com enclaves de urbano (colônias, loteamentos, condomínios), mas não há continuidade espacial entre eles.

As inúmeras modificações de atividades desenvolvidas nos territórios rurais e urbanos, desde a simples mudança de uso, até a crescente conversão das terras rurais em urbanas, dificultam o enquadramento da destinação do imóvel e a criação de zonas com atividades uniformes, existindo um conjunto de atividades desenvolvidas pelas famílias rurais que ultrapassam a concepção anterior de que essas apenas trabalhavam com atividades agrícolas ou rurais, sendo que hoje elas têm ocupações que geram emprego e renda, como a construção civil, artesanato, confecções, ou mesmo trabalham na área urbana, caracterizando a "pluriatividade" das famílias (SAULE, 2004, p. 50).

Joaquim Castro Aguiar entende que:

a fixação do perímetro urbano confere ao solo nele contido qualificação urbanística, mesmo que possua áreas ainda não urbanizadas, pois toda área do interior do perímetro urbano estará vocacionada para funções urbanísticas, sendo, pois, solo urbano[...]. O que não for zona urbana, rural será. A zona rural é compreendida entre o perímetro urbano e os limites territoriais do Município (AGUIAR, 1996, p. 89).

Conforme José Francisco Graziano da Silva (SILVA, 1997), o processo de urbanização brasileiro se desloca para o espaço rural, transformando-o. Segundo o autor, em muitos municípios, o espaço rural vem passando por profundas transformações, seja no avanço da modernização agrícola, seja no avanço de novas atividades no seu interior, havendo a urbanização do meio rural brasileiro, como resultado do processo de industrialização da agricultura e do transbordamento do mundo urbano no espaço que tradicionalmente era definido como rural.

Nesse panorama, houve a desintegração do rural tradicional, com a configuração de um novo rural mediante o processo de urbanização do espaço rural, observando-se uma nova dinâmica da produção agropecuária, sendo que a concepção do rural não se encontra mais 
vinculada à atividade estritamente agrícola, uma vez que a modernização das atividades agrícolas fomentou o desenvolvimento de atividades não agrícolas no campo (BERNARDES E ANTONELLO, 2009, p. 115).

Já se observa em vários países de capitalismo avançado, em especial países europeus, um repovoamento do espaço rural via atividades não agrícolas (descentralização industrial), local de moradia para aposentados e de lazer, entendido como um "renascimento rural" (BERNARDES E ANTONELLO, 2009, p. 116).

Conforme BERNARDES E ANTONELLO (2009, 116-117), os imóveis rurais não podem mais ser vistos como unidades fechadas de produção agrícolas, mas que, a partir das políticas públicas, podem se abrir para outras atividades como o turismo e a venda de produtos locais.

Nesse sentido, as relações campo-cidade ganham o significado de interconexão, não sendo possível mais falar do espaço urbano e rural como dicotômicos, mas sim como unidade dialética, havendo o nascimento de novas relações campo-cidade com o surgimento de um conjunto de atividades não voltadas somente para o agropecuário, mas também prestação de serviços e ocupações como turismo rural ou ecológico, comércio e indústria, bem como chácaras de lazer, desencadeando uma crescente valorização da terra (BERNARDES E ANTONELLO, 2009, p. 117).

Há também uma crescente conversão das terras rurais em urbanas, através da abertura de loteamentos habitacionais, ou mesmo da implantação de equipamentos de grande porte, como supermercados, postos de gasolina com lojas, indústrias ou distritos industriais, e a própria atividade rural pode desempenhar funções que não visam apenas a produção agrícola, mas a manutenção da biodiversidade, a preservação histórica, turísticas e outras, não diretamente caracterizadas como funções rurais stricto sensu (BERNARDES E ANTONELLO, 2009, p. 118).

$\mathrm{Na}$ falta de infraestrutura urbana na zona rural, os proprietários de imóveis passam a exigir do Poder Público Municipal diversos melhoramentos, como a extensão da rede de abastecimento de água, melhoria das estradas, transporte coletivo, coleta de lixo, sendo que em muitos casos não pagam tributos municipais, vez que os imóveis continuam vinculados à União, com o recolhimento de Imposto territorial rural - ITR.

A divisão que separa os municípios brasileiros em uma parte urbana e outra rural, por uma linha definida como perímetro urbano, só tem validade como critério objetivo de divisão 
territorial, não considerando a funcionalidade dos territórios demarcados e representando interesses citadinos e setoriais ligados às forças e grupos que exploram o capital imobiliário local, cuja demarcação tem implicação direta no mercado de terras, uma vez que a Lei Federal n. ${ }^{\circ}$ 6.766/79, em seu artigo 3. ${ }^{\circ}$, dispõe que “o parcelamento do solo só poderá ocorrer em área urbana, de expansão urbana ou urbanização específica" (SPAROVEK, 2004).

Assim, devemos deslocar a concepção de divisão do território e pensar o mesmo a partir de suas funções sociais, das vocações e necessidades dos habitantes. O disciplinamento do território, que é competência do município para as diversas finalidades, como a política tributária, deve ter como finalidade o pleno cumprimento das funções sociais da cidade e da propriedade (urbana e rural), de modo que seja redistribuída a riqueza e sejam combatidas as desigualdades sociais no campo e nas cidades brasileiras.

Os critérios que estabelecem o perímetro urbano e as áreas de expansão urbana deveriam advir de estudos de viabilidade urbanística e ambiental e não apenas da análise da viabilidade econômica como ocorre em muitos municípios brasileiros, gerando divisões que tornam ineficazes as ações públicas (SPAROVEK, 2004).

Ademais, a expansão indevida do perímetro urbano em área em que predomina a produção agrícola pode desestabilizar a atividade produtiva, sendo que propriedades passam a ser indevidamente fragmentadas, com o surgimento de loteamentos ilegais e a consequente elevação do preço de mercado das terras (SPAROVEK, 2004, p. 15).

Portanto, a área rural é de grande importância para muitos municípios e deve ser observada sua devida integração com a área urbana, através do ordenamento territorial a ser realizado pelo Poder Público Municipal, buscando ao atendimento das funções socioambientais da propriedade e da cidade que serão explicitadas a seguir.

\section{As Funções Socioambientais da propriedade e da cidade e a ocupação do imóvel rural para fins urbanos}

A propriedade para o Código Civil de 1916 não era condicionada ao cumprimento do bem-estar social, sendo dotada de proteção ao direito individual do proprietário e predominava o princípio da autonomia da vontade das partes.

Segundo Benedito Ferreira Marques (2015, 177-178), o direito de propriedade era constitucionalizado como um direito humano fundamental a ser protegido e respeitado pela legislação, sendo regulado pelo Código Civil como instrumento legislativo precípuo de proteção Depois, passou a ser tratado constitucionalmente como elemento da ordem 
econômica, cabendo à legislação ordinária definir seu regime jurídico, sendo que o direito de propriedade possui regime variável, estando conformado pela Constituição Federal, pelo Código Civil e pela legislação especial, ou seja, a propriedade terá um regime distinto conforme a natureza do bem que lhe sirva de objeto, sendo tal regime determinado tanto pela Constituição como por normas infraconstitucionais.

A Constituição de 1988, conhecida pelo seu caráter social, regulou a função social da propriedade nos artigos $5^{\circ}$, XXIII, dentro da concepção de direitos fundamentais; artigo 170, III, como princípio da ordem econômica; artigo $182, \S 2^{\circ}$, dentro da política urbana; e artigo 186, referente à política agrícola.

Segundo Rech (2010, p. 41), é possível identificar duas funções sociais distintas da propriedade, uma que está prevista no artigo 182, parágrafo 2. ${ }^{\circ}$, da Constituição Federal e que afirma que "a propriedade urbana cumpre sua função social quando atende às exigências fundamentais de ordenação da cidade expressa no pano diretor", que deve respeito ao uso adequado, na forma prevista no Plano Diretor. Já a função social da propriedade rural, destinada à finalidade agrária, segundo o autor, é prevista na Lei 8.629 de 1993, em seu artigo 9. ${ }^{\circ}$, mas, em relação à ocupação urbanística, tem sua função social complementada pelo Plano Diretor, diante dos interesses locais existente no município.

A Constituição Federal, em seu artigo 182, afirma ainda que "a política de desenvolvimento urbano executada pelo Município atenderá à função social da cidade e a garantia do bem-estar de seus habitantes", sendo da responsabilidade de cada cidade definir sua função social por meio do Plano Diretor, fixando princípios e diretrizes efetivadas através de zoneamentos, incentivos ou restrições de ocupação e de atividades (RECH, 2010, p. 42). Para Rech (2010, p. 42), a primeira função social da propriedade e da cidade é assegurar a cidadania e a dignidade da pessoa humana, tendo em vista que são princípios fundamentais eleitos pelo legislador constituinte, sendo necessária a edição de normas por parte do Poder Público municipal com o fim de garantir sua efetivação.

A propriedade da terra rural tem a finalidade de assegurar a política agrária, função social que não pode ser alterada, devendo ser observadas as normas de direito agrário em relação aos imóveis destinados à produção agropastoril e extrativista, mas em relação à ocupação da área rural para outras finalidades, como moradias, condomínios, comércio, indústria, turismo, lazer, agroindústria, construções em geral, com finalidades urbanas, devem ser regulamentada pelo Município, sendo de sua competência delimitar o perímetro urbano, a 
zona rural, as formas de ocupação, bem como onde e como pode haver ocupação com finalidades urbanas (RECH, 2010, p. 136), sendo o que preconiza o art. 30, inciso VIII, e o art. 182 da Constituição Federal.

Do contrário, haverá ocupação desordenada, vindo a ocasionar ônus ao Poder Público municipal ao ter que incluí-las como áreas urbanas ou ver descaracterizada a atividade agrária ou destruídas potencialidades locais, turísticas ou paisagísticas por construções clandestinas ao longo de rodovias ou localidades do interior (RECH, 2010, p. 137).

O exercício do direito de propriedade urbana é condicionado à política urbana que deve ser executada pelo Poder Público municipal com o objetivo de ordenar o pleno desenvolvimento das funções sociais da cidade e garantir o bem-estar de seus habitantes, nos termos do que dispõe o art. 182 da Constituição Federal (SAULE, 2004, p. 43).

No entanto, os municípios ignoram a possibilidade de legislar sobre a área rural, sendo que a ocupação rural, com características urbanas, fica desprovida de normas urbanísticas (RECH, 2010, p. 61).

O Decreto 62.504/68 já reconhecia que, além da atividade exclusivamente agrária, há a possibilidade de ocupações diversas e que devem ser legisladas pelo município, por ser de exclusivo interesse local. Caso este não estabeleça regras de ocupação, estará permitindo o caos, inviabilizando o direito subjetivo do cidadão de viver numa cidade ou município sustentável.

Dentre os assuntos de interesse local de competência do município, inclui-se a regulamentação administrativa de políticas públicas (art. 23 da Constituição Federal), devendo fomentar a produção agropecuária e organizar o abastecimento alimentar, definindo espaços destinados à produção e espaços de ocupação diversa, conforme o interesse local.

$\mathrm{Na}$ atual ordem constitucional brasileira, as cidades são consideradas bens ambientais, necessárias para o desenvolvimento e a qualidade de vida do ser humano, pois é nas urbes onde a maior parte da população brasileira vive e mantém relações sociais, fazendose, assim, necessária sua tutela no concernente às diretrizes gerais do art. 225 e dos arts. $182 \mathrm{e}$ 183 da Carta Magna nacional.

Conforme SUNDFELD (2006, p. 54),

A cidade, como espaço onde a vida moderna se desenrola, tem suas funções sociais: fornecer às pessoas moradia, trabalho, saúde, educação, cultura, lazer, transporte etc. Mas, como o espaço da cidade é parcelado, sendo objeto de apropriação tanto privada (terrenos e edificações) como estatal (ruas, praças, equipamentos etc.), suas funções têm de ser cumpridas pelas 
partes, isto é, pelas propriedades urbanas. A política urbana tem, portanto, a missão de viabilizar o pleno desenvolvimento das funções sociais do todo (a cidade) e das partes (cada propriedade em particular).

Dessa forma, somente é possível falar em cidade sustentável quando houver ocupação com equilíbrio ambiental, sendo este o objetivo do Estatuto da Cidade (RECH, 2010, p. 44), podendo assim ser entendida como sustentável a cidade que, respeitando características e limites sociais, econômicos e ambientais locais, promove a qualidade de vida de sua população, visando a mantê-la, também, para as gerações vindouras, satisfazendo, desta forma, a dignidade humana.

O Estatuto da Cidade, no parágrafo único de seu art. $1^{\circ}$, estabelece as diretrizes gerais da política urbana, que tem por objetivo ordenar o pleno desenvolvimento das funções sociais da cidade e da propriedade urbana em prol do bem coletivo, da segurança e do bemestar de seus cidadãos, bem como o equilíbrio ambiental.

Ressalte-se, no Estatuto da Cidade, a previsão, em seu art. $2^{\circ}$, I, da garantia do direito a cidades sustentáveis, nos seguintes termos:

Art. $2^{\circ}$ A política urbana tem por objetivo ordenar o pleno desenvolvimento das funções sociais da cidade e da propriedade urbana, mediante as seguintes diretrizes gerais:

I - garantia do direito a cidades sustentáveis, entendido como o direito à terra urbana, à moradia, ao saneamento ambiental, à infraestrutura urbana, ao transporte e aos serviços públicos, ao trabalho e ao lazer, para as presentes e futuras gerações; (...)

Esta norma positiva, no ordenamento jurídico brasileiro, a garantia de sustentabilidade urbana. A respeito deste direito, o Estatuto da Cidade - Guia para Implementação pelos Municípios e Cidadãos (BRASIL, 2002, p. 163), estende um pouco mais a sua já larga amplitude:

O direito a cidades sustentáveis - entendido como o direito aos meios de subsistência, à moradia, ao saneamento, à saúde, à educação, ao transporte público, à alimentação, ao trabalho, ao lazer e à informação. Inclui também o direito à liberdade de organização, o respeito às minorias e a pluralidade étnica, sexual e cultural, o respeito aos imigrantes e o reconhecimento de sua plena cidadania, a preservação da herança histórica e cultural e o direito ao usufruto de um espaço culturalmente rico e diversificado, sem distinções de gênero, nação, raça, linguagem e crenças e ao meio ambiente ecologicamente equilibrado.

Por ser uma diretriz geral da política urbana nacional, o direito às cidades deve ser respeitado e implementado tanto pela União quanto por Estado e Município. A este último, no 
entanto, cabe a maior parcela da concretização da referida norma, pois cada cidade tem características, problemas e necessidades próprios, sendo o governo local o mais indicado para a solução dessas situações justamente por conta da proximidade com a problemática em concreto:

Em verdade, as normas urbanísticas municipais são as mais características, porque é nos municipios que se manifesta a atividade urbanística na sua forma mais concreta e dinâmica. Por isso, as competências da União e do Estado esbarram na competência própria que a Constituição reservou aos Municípios, embora estes tenham, por outro lado, que conformar sua atuação urbanística aos ditames, diretrizes e objetivos gerais do desenvolvimento urbano estabelecidos pela União e às regras genéricas de coordenação expedidas pelo Estado. (SILVA, 2010, p. 63)

O direito a cidades sustentáveis busca garantir à população urbana melhor qualidade de vida e, em consequência, realizar a dignidade da pessoa humana, representando um avanço no ordenamento jurídico pátrio. Por tudo isso, deve ser considerado como um direito fundamental a ser efetivado pelo Poder Público.

Segundo Rech (2010, p. 134), não há como falar em sustentabilidade da cidade sem uma área rural planejada, com zoneamentos de interesse local definidos, como zonas de produção incentivadas, localização de agroindústrias regulamentadas, zonas potenciais de expansão urbana bem delimitadas, zoneamentos ambientais de interesse local preservados, sistema viário adequado e normatizado pelo município, bem como regras de ocupação habitacional, com o fim de evitar ocupações que comprometam a sustentabilidade das presentes e futuras gerações.

Nesse sentido, é necessária a devida ordenação pelo Município quanto às atividades permitidas ou proibidas, visando atender ao princípio da sustentabilidade e em proteção à cidadania.

Por fim, calha referência à alteração introduzida pela lei n. ${ }^{\circ} 12.608$, de 10 de abril de 2012, que criou o artigo 42-B do Estatuto da Cidade $^{3}$, no sentido da realização de uma série

\footnotetext{
${ }^{3}$ Art. 42-B. Os Municípios que pretendam ampliar o seu perímetro urbano após a data de publicação desta Lei deverão elaborar projeto específico que contenha, no mínimo: (Incluído pela Lei n 12.608, de 2012)

I - demarcação do novo perímetro urbano;

II - delimitação dos trechos com restrições à urbanização e dos trechos sujeitos a controle especial em função de ameaça de desastres naturais;

III - definição de diretrizes específicas e de áreas que serão utilizadas para infraestrutura, sistema viário, equipamentos e instalações públicas, urbanas e sociais;

IV - definição de parâmetros de parcelamento, uso e ocupação do solo, de modo a promover a diversidade de usos e contribuir para a geração de emprego e renda;
} 
de medidas sustentáveis para a expansão dos perímetros urbanos dos municípios, com requisitos indispensáveis para evitar a ampliação indevida do perímetro urbano que possa vir a causar degradação ambiental e ônus para os municípios.

Quanto ao imóvel rural, observa-se que o artigo $2^{\circ}$ do Estatuto da Terra, em seu caput, assegura a todos os cidadãos o acesso à propriedade da terra e, ao mesmo tempo, condiciona este acesso à função social desta propriedade, dentro do que prevê esta lei. Já em seu $\S 1^{\circ}$ e alíneas, apregoa exatamente o que dispõe nossa carta magna em seu artigo 186 e alíneas.

Vale destacar os requisitos legais acerca da função social da propriedade rural, sendo que os parágrafos do art. $9^{\circ}$ da Lei n. ${ }^{\circ} 8.629 / 1993$ apresentam critérios mais objetivos no que se refere à função social da propriedade, com destaque para a adequada utilização dos recursos naturais e a preservação do meio ambiente, exigindo o respeito à vocação natural da terra, com vistas à manutenção tanto do potencial produtivo do imóvel como das características próprias do meio natural e da qualidade dos recursos ambientais, visando ao equilíbrio ecológico da propriedade e, ainda, à saúde e qualidade de vida das comunidades vizinhas (MARQUES, 2015, P. 54-55).

Assim, incumbe ao poder público o dever de cuidar para que a propriedade urbana e a rural atinjam o objetivo proposto pelo legislador, objetivo este que tem como propulsor o bem estar da coletividade, em atendimento às funções socioambientais da propriedade e da cidade, bem como o adequado ordenamento territorial e desenvolvimento do município.

\section{Competências e atribuições dos entes públicos na implementação do ordenamento territorial e desenvolvimento sustentável dos municípios}

\footnotetext{
V - a previsão de áreas para habitação de interesse social por meio da demarcação de zonas especiais de interesse social e de outros instrumentos de política urbana, quando o uso habitacional for permitido;

VI - definição de diretrizes e instrumentos específicos para proteção ambiental e do patrimônio histórico e cultural; e VII - definição de mecanismos para garantir a justa distribuição dos ônus e benefícios decorrentes do processo de urbanização do território de expansão urbana e a recuperação para a coletividade da valorização imobiliária resultante da ação do poder público.

$\S \mathbf{1}^{\circ} \mathrm{O}$ projeto específico de que trata o caput deste artigo deverá ser instituído por lei municipal e atender às diretrizes do plano diretor, quando houver.

$\$ 2^{\mathbf{0}}$ Quando o plano diretor contemplar as exigências estabelecidas no caput, o Município ficará dispensado da elaboração do projeto específico de que trata o caput deste artigo.

$\S 3^{\circ} \mathrm{A}$ aprovação de projetos de parcelamento do solo no novo perímetro urbano ficará condicionada à existência do projeto específico e deverá obedecer às suas disposições.
} 
No atual regime democrático federativo instaurado pela Constituição Federal de 1988, há repartição de competências, de acordo com a capacidade das três esferas para o exercício eficiente de determinadas atividades de interesse público.

Conforme NAKANO (2004, p. 41-42),

A União tem a competência para instituir as diretrizes gerais para o desenvolvimento urbano, habitação, saneamento básico e transportes urbanos (art. 21, XX) e sobre normas gerais de direito urbanístico (art. 24, I), sendo instituídas as diretrizes gerais através do Estatuto da Cidade. As diversas atividades e funções existentes nas cidades e no campo de interesse e de necessidade dos habitantes nos municípios são consideradas como de competência comum entre a União, estados e município, de acordo com o art. 23 da Constituição Federal, entre elas: Cuidar da saúde e assistência pública; Proporcionar os meios de acesso à cultura, à educação e à ciência; Preservar as florestas, a fauna e a flora; Proteger o meio ambiente $e$ combater a poluição em qualquer de suas formas; Fomentar a produção agropecuária e organizar o abastecimento alimentar; Promover programas de construção de moradias e a melhoria das condições habitacionais e de saneamento básico; Combater as causas da pobreza e os fatores de marginalização, promovendo a integração social dos setores desfavorecidos.

Ao município, nos termos do art. 30 da Constituição Federal, foi conferida a competência para legislar sobre assuntos de interesse local e suplementar a legislação federal e estadual no que couber, podendo criar, organizar e suprimir distritos, observada a legislação estadual; organizar e prestar os serviços públicos de interesse local, incluído o de transporte coletivo.

Nas lições de Hely Lopes Meirelles,

(...) interesse local não é interesse exclusivo do Município, não é interesse privativo da localidade, não é interesse único dos munícipes (...). Não há interesse municipal que não seja reflexamente da União e do EstadoMembro, como também não há interesse regional ou nacional que não ressoe nos municípios, como partes integrantes da federação brasileira. $O$ que define e caracteriza interesse local, inscrito como dogma constitucional é a preponderância do interesse do Município sobre o do Estado ou da União (BASTOS, 2001, p. 319).

Quanto à execução da política urbana e ordenamento territorial, nos termos do que dispõe a Constituição Federal, compete aos Municípios promover, no que couber, adequado ordenamento territorial, mediante planejamento e controle do uso, parcelamento e da ocupação do solo urbano (art. 30, VIII, CF) e executar a política de desenvolvimento urbano, 
conforme diretrizes fixadas em lei, tendo como objetivo ordenar o pleno desenvolvimento das funções sociais da cidade e garantir o bem-estar de seus habitantes (art. 182, CF).

Hoje, a área rural não é objeto de licenciamento administrativo e ambiental por parte do município, enquanto que as implicações socioeconômicas e ambientais nessa área são de suma importância por constituírem a maior porção do território na maioria dos municípios brasileiros, utilizando grande parte dos recursos naturais (RECH, 2010, 139).

A delimitação entre rural e urbano é realizada pelo município, mas não impede a ocupação da zona rural por atividades com características urbanas, sendo que, em vários municípios e regiões do país, a realidade rural não se restringe às atividades agrícolas, notando-se o desenvolvimento de setores não agrícolas em estreitas relações com as atividades instaladas nas cidades, motivo pelo qual os municípios precisam realizar o planejamento e gestão de seus territórios a fim de evitar que se acumulem, no futuro, déficits sociais e passivos ambientais (NAKANO, 2004, p. 26 e 28).

Conforme Nakano (2004, p. 29), necessária uma leitura socioterritorial da zona rural orientada pelos objetivos e diretrizes do Plano diretor, expressos no macrozoneamento urbano e rural, analisando as tendências de desenvolvimento das atividades agrícolas e não agrícolas, bem como as possibilidades de uso e ocupação para fins diversos.

Afirma o autor (NAKANO, 2004, p. 34 e 39) que o município tem a responsabilidade constitucional de legislar sobre assuntos de interesse local, sendo que a regulação das formas de uso, ocupação e parcelamento do solo no território municipal é de interesse local, motivo pelo qual o município deve tomar para si a responsabilidade de exercer essa regulação, existindo várias possibilidades de incrementar a integração urbano-rural e de promover sinergias entre suas atividades.

É função do Município definir os critérios para a cidade e a propriedade urbana atender à sua função social, nos termos do art. 182 da Constituição, que condiciona a atuação do Poder Público municipal à observância da lei federal de desenvolvimento urbano (Estatuto da Cidade) e ao Plano Diretor, sendo este o principal instrumento da política de desenvolvimento urbano, afirmando ainda que o adequado ordenamento territorial do município pressupõe que o município tenha o poder de disciplinar o uso, a ocupação e o parcelamento do solo de todo o seu território (NAKANO, 2004, p. 42 e 44).

Não há dúvida que a competência sobre a política agrícola e agrária é da União (pelo art. 22, I, da Constituição Federal, é competência privativa da União legislar sobre direito 
agrário), mas é necessário haver uma nítida integração entre a questão urbana e a questão agrária, sendo que a dimensão do crescimento urbano demonstra a necessidade de modificar as relações sociais e econômicas para que se promova o desenvolvimento econômico em consonância com os ditames da justiça social, cuja modificação passa pela realização da reforma urbana, articulada com reforma agrária, em vista da relação estreita entre a questão rural, urbana e ambiental (NAKANO, 2004, p. 46).

Assim, não é possível separar o urbano e o rural, visando garantir o pleno desenvolvimento das funções sociais da cidade, pois o sistema social e econômico local necessita dos equipamentos, da infra-estrutura e dos serviços urbanos para desenvolver suas atividades agrícolas e agrárias na zona rural da cidade.

Esta dependência da produção rural evidencia a necessidade de um ordenamento do uso e ocupação do solo rural, visando à obtenção do uso equilibrado das fontes de recursos e ao adequado manejo socioambiental e econômico.

Assim, as construções em zona rural não podem ser feitas sem critérios urbanísticos e em qualquer lugar desprovido de normas de ocupação, sendo que os municípios devem buscar assegurar a sustentabilidade, estabelecendo regras tais como zoneamento e índices construtivos para que não seja descaracterizada a função social da propriedade a fim de realizar a organização de seu território e fomentar as potencialidades econômicas, naturais e turísticas locais, bem como evitar construções em locais inadequados e que possam colocar em risco o princípio da sustentabilidade ambiental, econômica e social do município (RECH, 2010, p. 150 e 153).

O zoneamento da área rural deve observar o Estatuto da Terra, mas como a ocupação com fins urbanos é de interesse local, é necessário seja regulamentada pelos municípios quanto aos índices construtivos, afastamentos das vias municipais, ordenando atividades permitidas ou proibidas, diante do princípio da sustentabilidade e em proteção à cidadania (RECH, 2010, p. 149).

Necessária, assim, a realização do adequado ordenamento territorial pelos municípios com a inclusão das áreas existentes na zona rural, visando regular seu uso e ocupação, em especial em relação às atividades com características urbanas, buscando a sustentabilidade através do equilíbrio ambiental, social e econômico.

\section{O Estatuto da Cidade e o Plano Diretor sobre todo o território do município}


Hoje na área rural tudo é permitido e nada é previamente planejado e controlado pelo Poder Público municipal, sendo que há ocupação para fins urbanos cujo parcelamento do solo é feito à revelia da legislação agrária e não observa qualquer legislação urbana que inexiste na maioria dos municípios em relação à ocupação com fins urbanos na zona rural.

A zona rural tem sido ocupada indevidamente, por não haver regras de ocupação e organização, constituindo-se em locais de miséria, com habitações irregulares, onde há falta de estrutura e degradação ambiental (RECH P. 154).

Sua regulamentação pelos municípios surge da necessidade de que tal ocupação ocorra de forma organizada e em locais adequados, evitando ocupações sem normas, que venham desvirtuar as diretrizes do município e causar danos ao meio ambiente.

O Estatuto da Cidade, ao regulamentar o capítulo constitucional referente à política urbana, enfatiza a necessidade de planejamento do desenvolvimento das cidades, a garantia da sustentatibilidade, a gestão democrática, a cooperação entre os atores púbicos e privados, a ordenação e controle do uso do solo, a integração e complementariedade entre atividades urbanas e rurais, dentre outras diretrizes, com o objetivo de garantir o bem estar das gerações presentes e futuras, havendo uma ênfase notória na idéia de que o plano diretor é o instrumento básico da política de desenvolvimento e expansão urbana que deverá englobar todo o território do município, bem como a primazia do poder público municipal na condução da política de desenvolvimento urbano ${ }^{4}$.

Mesmo após o advento do Estatuto da Cidade (Lei 10.257, de 10 de julho de 2001), os planos diretores dos municípios continuam a excluir a área rural, inexistindo um planejamento efetivo por parte do Município, bem como inexiste o controle municipal da ocupação na referida área, não se definindo o zoneamento, índices construtivos, sistema viário, áreas institucionais, formas de ocupação, etc, aplicando-se tão somente a legislação agrária e ambiental estadual e federal. (RECH, 2010, p. 140).

De acordo com o $\S 2^{\circ}$ do art. 40 do Estatuto da Cidade ${ }^{5}$, o Plano Diretor deverá englobar o território do município como um todo, ou seja, deve abranger tanto a zona urbana como a zona rural do município.

\footnotetext{
${ }^{4}$ Conforme NOTA TÉCNICA INCRA/DF/DFC/N. ${ }^{\circ}$ 02/2016, expedida com o fim de esclarecer acerca das competências do Município e do INCRA em razão da revogação da Instrução Normativa n. ${ }^{\circ} 17-b$, de 22 de dezembro de 1980 pela Instrução Normativa 82, de 27 de março de 2015.

5 Art. 40. O plano diretor, aprovado por lei municipal, é o instrumento básico da política de desenvolvimento e expansão urbana.

$\S 1^{\circ}(. .$.
} 
Assim, o Estatuto da Cidade define a abrangência territorial do Plano Diretor de forma a contemplar as zonas rurais, com respaldo no texto constitucional, uma vez que a política urbana, de acordo com a diretriz prevista no inciso VII do art. $2^{\circ}$ do Estatuto da Cidade, deve promover a integração e a complementaridade entre atividades urbanas e rurais, tendo em vista o desenvolvimento socioeconômico do município e do território sob sua área de influência.

Conforme RECH (2010, p. 145 e 149), a Constituição, ao prescrever que a política de desenvolvimento urbano tem por objetivo ordenar o pleno desenvolvimento das funções sociais da cidade e garantir o bem-estar de seus habitantes, não diferencia os habitantes situados na zona rural, dos situados na zona urbana, sendo que a realidade das cidades demonstra, cada vez mais, uma estreita ligação entre as atividades promovidas na zona rural com as atividades urbanas, uma vez que grande parte da população que vive na zona rural tem seu emprego e trabalho na região urbana, sem contar a utilização da infra-estrutura e serviços urbanos, como o transporte coletivo, escolas, postos de saúde, hospitais, comércio e lazer, sendo que o Município, através do Plano diretor, deve buscar garantir uma cidade sustentável e o meio ambiente ecologicamente equilibrado para seus munícipes.

Apesar de a Constituição Federal ter previsto a obrigatoriedade do plano diretor apenas para as cidades com mais de 20.000 habitantes, o Estatuto de Cidade (art. 41) ampliou tal rol para também englobar as urbes integrantes de regiões metropolitanas e aglomerações urbanas; as cidades onde o Poder Público municipal pretenda utilizar os instrumentos previstos no $\S^{\circ}$ do art. 182 da Constituição Federal; as integrantes de áreas de especial interesse turístico e as inseridas na área de influência de empreendimentos ou atividades com significativo impacto ambiental de âmbito regional ou nacional.

Com o objetivo de estabelecer um tratamento isonômico aos habitantes do município, o município deve adotar um Plano Diretor que seja voltado à promoção do desenvolvimento local sustentável, abrangendo a totalidade do seu território (SAULE, 2004, p. 43).

José Afonso da Silva (SILVA, 2008, p. 139), ao analisar a nomenclatura plano diretor, afirma o seguinte:

§ 2. ${ }^{\circ} \mathrm{O}$ plano diretor deverá englobar o território do Município como um todo. 
É plano, porque estabelece os objetivos a serem atingidos, o prazo em que estes devem ser alcançados (ainda que, sendo plano geral, não precise fixar prazo, no que tange às diretrizes básicas), as atividades a serem executadas $e$ quem deve executá-las. É diretor, porque fixa as diretrizes do desenvolvimento urbano do Município.

O Estatuto da Cidade também instituiu o conteúdo mínimo a ser previsto no plano diretor, sob pena de perda de sua natureza em caso de ausência:

Art. 42. O plano diretor deverá conter no mínimo:

I - a delimitação das áreas urbanas onde poderá ser aplicado o parcelamento, edificação ou utilização compulsórios, considerando a existência de infraestrutura e de demanda para utilização, na forma do art. $5^{\circ}$ desta Lei;

II - disposições requeridas pelos arts. 25, 28, 29, 32 e 35 desta Lei;

III - sistema de acompanhamento e controle.

É indispensável a qualificação urbanística do terreno pelo plano diretor, sendo que o zoneamento local da área rural, além de assegurar a proteção do meio ambiente, pode ter interesses econômicos, como o incremento do turismo ou de atividade extrativista, como a colheita do pinhão na serra gaúcha ou do açaí no Nordeste brasileiro (RECH, 2010, p. 143).

Segundo Rech (2010, P. 159-160), o Plano Diretor municipal, à medida em que há o aumento na densidade demográfica na área rural, deve prever a necessidade de áreas institucionais destinadas à concretização dessas finalidades de interesse público, buscando atender populações locais da área rural, sendo que o Estatuto da Cidade estabeleceu como direito subjetivo o desenvolvimento sustentável, imputando dever ao Poder Público de disponibilizar a infraestrutura de transporte, serviços públicos, trabalho e lazer para as presentes e futuras gerações, não apenas para a população urbana como também para a rural.

Nesse sentido, o município pode, através do Plano Diretor, limitar o percentual da área rural, de acordo com o tamanho do módulo previsto na legislação agrária, para fins de ocupação urbana, buscando não descaracterizar a atividade econômica de produção primária, mas com o fim de estabelecer limites para a ocupação de caráter urbano, estabelecendo zoneamentos ou cota da área ou módulo rural onde poderá haver construções de moradia ou de atividades complementares de sustentabilidade, com características urbanas, podendo ser fixados índices de ocupação e índices construtivos sem que se interfira na competência exclusiva da União em legislar sobre direito agrário, uma vez que está se tratando de ocupação de caráter urbano e sustentabilidade, cuja regulação é de competência do Poder Público municipal (RECH, 2010, p. 159). 
Conforme Rech (2010, p. 139), pode ainda o município estabelecer normas regulamentadoras da construção civil na área rural, com índices construtivos de acordo com o zoneamento estabelecido no plano diretor, como zonas de produção, zonas de proteção ambiental, zonas de desenvolvimento do turismo, zonas de preservação histórica e cultural, faixas de domínio de vias de escoamento da produção, dentre outras.

Para o município promover a política de desenvolvimento urbano, o Plano Diretor deve ser entendido como um instrumento de desenvolvimento local sustentável com normas voltadas a abranger a totalidade do seu território, compreendendo a área urbana e rural, padecendo de vício constitucional o Plano Diretor que se restringir apenas à zona urbana e de expansão urbana.

Assim, necessário que o Município assuma sua competência no ordenamento territorial, com a gestão integral do território municipal através de normas como o plano diretor, incluindo a zona rural em suas diretrizes, com o fim de estabelecer regras de ocupação e de interesse local também na área rural.

\section{Considerações finais}

Diante de todo o exposto, tem-se que hoje não há a efetiva aplicação das normas urbanísticas para as ocupações com fins urbanos na zona rural da maior parte dos municípios brasileiros, permanecendo omisso o Município quanto ao devido ordenamento territorial da zona rural.

A expansão indevida do perímetro urbano em área rural pode desestabilizar a atividade produtiva e causar degradação do meio ambiente natural e urbano, sendo que propriedades passam a ser indevidamente fragmentadas, com o surgimento de loteamentos ilegais sem a devida infraestrutura, havendo a consequente elevação do preço de mercado das terras, motivo pelo qual é necessário maior controle por parte do Poder Público em relação à crescente conversão das terras rurais em urbanas.

Nesse contexto, necessário que o Poder público municipal busque a efetivação do direito a cidades sustentáveis como um direito fundamental que está intrinsicamente ligado à qualidade de vida e a dignidade dos seres humanos, previsto implicitamente na Constituição brasileira e positivado em lei (Estatuto da Cidade), sendo que seu principal instrumento de efetivação é o plano diretor, que deve buscar promover o desenvolvimento e a expansão urbana de forma socialmente justa e ambientalmente equilibrada. 
A busca da sustentabilidade deve considerar a inter-relação e a complementariedade que há entre os espaços urbano e rural, visando garantir o pleno desenvolvimento das funções sociais da cidade, motivo pelo qual necessária a intervenção por parte do Município, abrangendo toda a sua população, devendo considerar todo o seu território para promover seu adequado ordenamento e o desenvolvimento sustentável do município.

O município tem a responsabilidade constitucional de legislar sobre assuntos de interesse local, sendo que a regulação das formas de uso, ocupação e parcelamento do solo no território municipal é, inegavelmente, de interesse local e deve ser da responsabilidade do Município buscar soluções e uma melhor gestão e planejamento do seu território como um todo, com a aplicação efetiva das diretrizes do Estatuto da Cidade e do Plano Diretor, com a implementação do direito à cidade sustentável.

O disciplinamento do território, que é competência do município, deve ter como finalidade o pleno cumprimento das funções sociais da cidade e da propriedade (urbana e rural), de modo que seja redistribuída a riqueza e sejam combatidas as desigualdades sociais no campo e nas cidades brasileiras.

\section{Referências bibliográficas}

AGUIAR, Joaquim Castro. Direito da cidade. Rio de Janeiro: Renovar, 1996.

BASTOS, Celso Ribeiro. Curso de Direito Constitucional. 22a ed. São Paulo: Saraiva, 2001. BERNARDES, Jamile Ruthes; ANTONELLO Ideni Terezinha. A interface entre a implantação de chácaras para lazer e a constituição do "Novo Rural brasileiro". CampoTerritório: Revista de Geografia Agrária, V.4, N.7, p. 112-139, 2009.

BRASIL. Constituição (1988): promulgada em 5 de outubro de 1988. Disponível em: http://www.planalto.gov.br/ccivil_03/constituicao/constituicaocompilado, Acesso em: 05 mai. 2017.

Lei $\mathrm{n}^{\mathrm{o}}$ 4.504, de 30 de novembro de 1964. Disponível em: <http://www.planalto.gov.br/ccivil_03/leis/L4504.htm>. Acesso em: 12 mai. 2017.

Lei n. ${ }^{\circ}$ 5.172, de 25 de outubro de 1966. Disponível em: <http://www.planalto.gov.br/ccivil_03/leis/L5172.htm>. Acesso em: 12 mai. 2017.

. Lei $\mathrm{n}^{\circ} 8.629$, de 25 de fevereiro de 1993. Disponível em: <http://www.planalto.gov.br/ccivil_03/leis/L8629.htm>. Acesso em: 29 abr. de 2017.

. Estatuto da cidade (2002). Estatuto da cidade: guia para implementação pelos municípios e cidadãos: Lei n. 10.257, de 10 de julho de 2001, 2. ed., Brasília: Câmara dos Deputados, Coordenação de Publicações, 2002. 
DIAS, Daniella Maria dos Santos. Planejamento e desenvolvimento urbano no sistema jurídico brasileiro: óbices e desafios. Curitiba, Juruá, 2012, p. 56.

INCRA, Nota Técnica INCRA/DF/DFC/n. ${ }^{\circ}$ 02/2016.

MARQUES, Benedito Ferreira. Direito Agrário Brasileiro. 11. ed. rev. e ampl. São Paulo: Atlas, 2015.

NAKANO, K. O Plano Diretor e as zonas rurais. In SANTORO, Paula \& PINHEIRO, Edie (Orgs.), O município e as áreas rurais. São Paulo: Instituto Pólis, 2004.

RECH, Adir Ubaldo; RECH, Adivandro. Direito Urbanístico: Fundamentos para a construção de um Plano Diretor sustentável na área urbana e rural. Caxias do Sul: Educs, 2010.

SANTORO, Paula \& PINHEIRO, Edie (Orgs.). O município e as áreas rurais. São Paulo: Instituto Pólis, 2004.

SAULE JR, Nelson. A competência do município para disciplinar o território rural. In SANTORO, Paula \& PINHEIRO, Edie (Orgs.), O município e as áreas rurais. São Paulo: Instituto Pólis, 2004.

SILVA, José Francisco Graziano da. O novo rural brasileiro. Belo Horizonte: Nova Economia (UFMG), v. 7, n.1, p. 43-82, 1997.

SILVA. José Afonso. Direito Urbanístico Brasileiro. 5. Ed. São Paulo: Malheiros, 2008.

SPAROVEK, G.; LEONELLI, G. C. V.; BARRETTO, A. G. O. P. A linha imaginária. In: SANTORO, P.; PINHEIRO, E. (Org.). O planejamento do município e o território rural. São Paulo: Instituto Pólis, 2004. 